\title{
Thymic Function and T-Cell Receptor Repertoire Diversity: Implications for Patient Response to Checkpoint Blockade Immunotherapy
}

\author{
Antonella Cardinale ${ }^{1+}$, Carmen Dolores De Luca ${ }^{2+}$, Franco Locatelli ${ }^{1,2}$ \\ and Enrico Velardi ${ }^{1 *}$ \\ ${ }^{1}$ Department of Pediatric Hematology and Oncology, Bambino Gesù Children's Hospital, Istituto di Ricovero e Cura a \\ Carattere Scientifico (IRCCS), Rome, Italy, ${ }^{2}$ Department of Maternal and Child Health, Sapienza University of Rome, \\ Rome, Italy
}

\section{OPEN ACCESS}

Edited by:

Roberta Zappasodi,

Cornell University, United States

Reviewed by:

Kellie Smith,

Johns Hopkins University,

United States

Ann Chidgey,

Monash University, Australia

*Correspondence:

Enrico Velardi

enrico.velardi@opbg.net

${ }^{\dagger}$ These authors have contributed

equally to this work

Specialty section:

This article was submitted to

Cancer Immunity and Immunotherapy,

a section of the journal

Frontiers in Immunology

Received: 02 August 2021 Accepted: 05 November 2021 Published: 24 November 2021

Citation:

Cardinale A, De Luca CD, Locatelli F and Velardi E (2021) Thymic Function and T-Cell Receptor Repertoire Diversity: Implications for Patient Response to Checkpoint

Blockade Immunotherapy.

Front. Immunol. 12:752042. doi: 10.3389/fimmu.2021.752042
The capacity of $T$ cells to recognize and mount an immune response against tumor antigens depends on the large diversity of the T-cell receptor (TCR) repertoire generated in the thymus during the process of T-cell development. However, this process is dramatically impaired by immunological insults, such as that caused by cytoreductive cancer therapies and infections, and by the physiological decline of thymic function with age. Defective thymic function and a skewed TCR repertoire can have significant clinical consequences. The presence of an adequate pool of $T$ cells capable of recognizing specific tumor antigens is a prerequisite for the success of cancer immunotherapy using checkpoint blockade therapy. However, while this approach has improved the chances of survival of patients with different types of cancer, a large proportion of them do not respond. The limited response rate to checkpoint blockade therapy may be linked to a suboptimal TCR repertoire in cancer patients prior to therapy. Here, we focus on the role of the thymus in shaping the T-cell pool in health and disease, discuss how the TCR repertoire influences patients' response to checkpoint blockade therapy and highlight approaches able to manipulate thymic function to enhance anti-tumor immunity.

Keywords: immune reconstitution, thymus, immunotherapy, TCR repertoire diversity, T cells

\section{INTRODUCTION}

Optimal immunological response to a large array of unknown antigens requires the presence of a diverse T-cell receptors (TCRs) repertoire, which represents the primary determinant for the likelihood of recognizing specific antigens (1). The thymus is the primary lymphoid organ with the exclusive role for generating and maintaining in the periphery a broadly diverse pool of $\mathrm{T}$ cells able to recognize tumor and pathogenic antigens. Once considered to take only a marginal part in maintaining a healthy immune system in adult life, the adult thymus plays a crucial role in sustaining the peripheral TCR repertoire diversity under physiological and clinical conditions. Thymic function and $\mathrm{T}$-cell output are dynamic processes that can be severely compromised by 
acute immunological insults (resulting from infections, stress or antineoplastic therapies) and by chronic dysfunctions (such as the ones correlated to age-associated involution and recurrent infections). Suboptimal thymic function and skewed TCR repertoire can have profound immunological and clinical consequences for patients' response to different forms of immunotherapy (Figure 1).

\section{THYMIC FUNCTION AND THE GENERATION OF A DIVERSE TCR REPERTOIRE}

During the process of T-cell development, thymocytes undergo a series of well-characterized and sequential developmental steps that ultimately lead to the formation of CD4 or CD8 singlepositive T cells. These developmental steps are orchestrated by the crosstalk between bone marrow (BM)-derived T-cell progenitors and the supportive thymic stromal microenvironment, which primarily consists of thymic epithelial cells (TECs), endothelial cells (ECs), mesenchymal cells, dendritic cells and macrophages (2). A crucial step in T-cell development process is the generation of TCR molecules able to recognize antigenic peptides presented on heterologous cells. The recognition of a specific antigen is granted by three complementarity-determining regions (CDRs) of the TCR. The CDR3 regions are generated by somatic rearrangement between noncontiguous variable $(\mathrm{V})$ and joining (J) gene segments for $\alpha$ and $\gamma$ loci and between $V$, diversity (D), and $\mathrm{J}$ segments for the $\beta$ and $\delta$ loci. The existence of multiple V, D and J gene segments in germline DNA allows the generation of a large variety of distinct CDR3 sequences that can be encoded (3). TCR rearrangement occurs in the thymic cortical and medullary regions where, respectively, the positive and negative selection of developing thymocytes occurs (4). Once the formation of a functional TCR is completed, T cells leave the thymus and enter the circulation where they impact the peripheral TCR diversity, specifically, of the naïve T-cell compartment.

The integrity of thymic function is essential for the generation of $\mathrm{T}$ cells with a diverse TCR. However, the thymus is particularly susceptible to negative insults that can come from infections, stress, acute and chronic Graft-versus-Host disease,

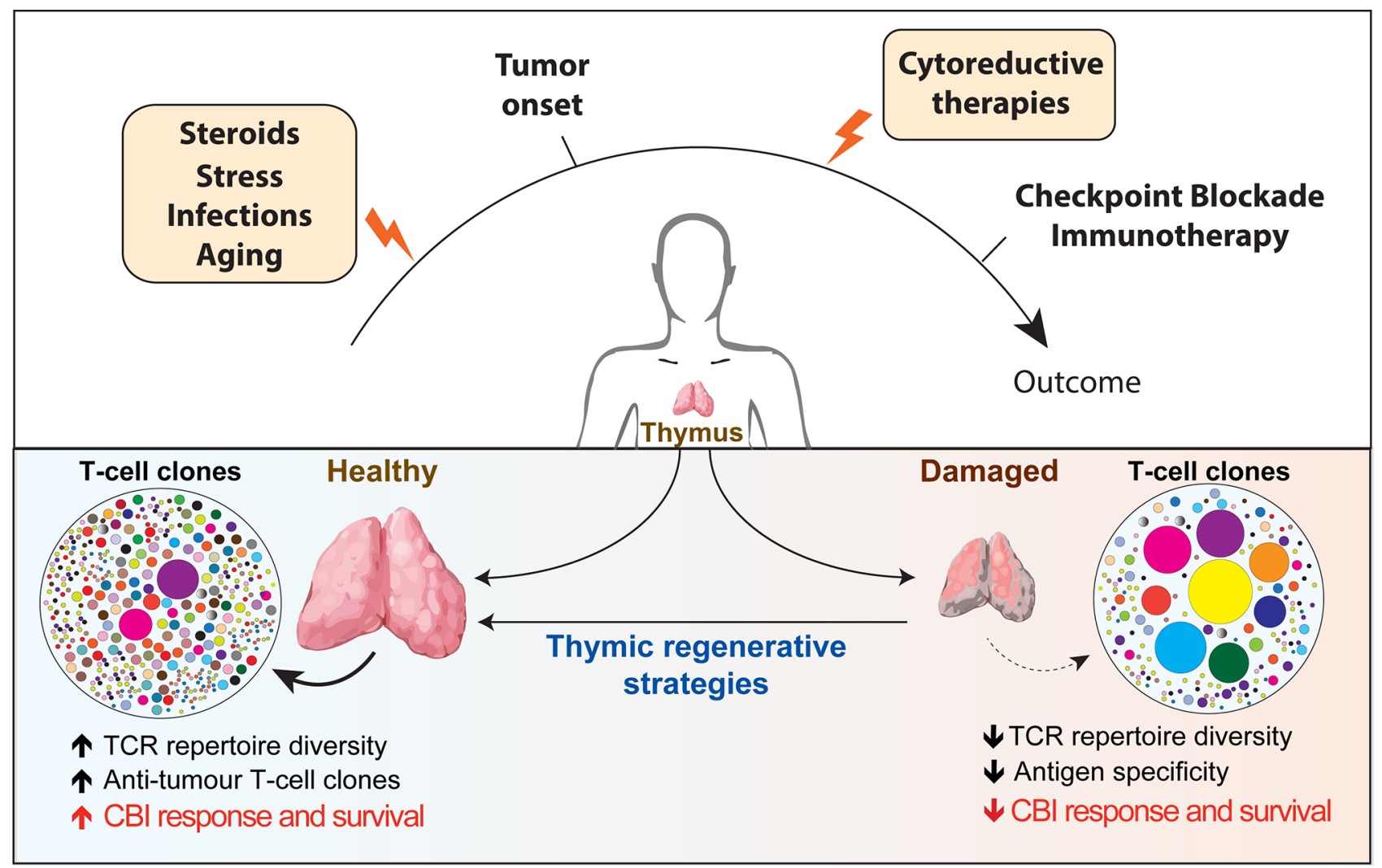

FIGURE 1 | Overview of the factors affecting thymic function and their potential role in regulating patients' response to checkpoint blockade immunotherapy. Thymus is particularly sensitive to negative insults that can come from infections, stress, cytoreductive therapies and the physiological process of aging (yellow boxes). The reduction in thymic functionality and in the TCR diversity impaired immune surveillance and may provide a supportive environment for tumors to elude T-cell-mediated response. Instead, a broader TCR repertoire in patients receiving CBI would increase the chance of tumor antigen recognition and favorable longterm clinical outcome. The use of regenerative factors aimed to boost thymic function could improve TCR repertoire diversity and have the potential to significantly extend the clinical efficacy of CBI. TCR, T cell repertoire; CBI, checkpoint blockade immunotherapy; SSA, sex steroids ablation. 
cytoreductive therapies such as chemo and radiotherapy (5). These effects lead to a qualitative and quantitative decline in Tcell output with consequent restricted TCR repertoire diversity and impaired immune responses. At a specific time of an individual's life, the peripheral diversity of TCR repertoire reflects and is shaped by multiple intrinsic and extrinsic factors, including the residual thymic functionality, previous response to pathogens, previous diseases and therapies, and many others.

In addition, the physiological process of aging has important effects on thymic function and TCR diversity. While the adult thymus can still generate new T cells up to the seventh decade of life, this process is severely compromised (6-8). It is well recognized that the size of peripheral naïve $\mathrm{T}$-cell pool and the functionality of the immune system progressively decline with age (9). Particularly, aging impairs the normal process of T-cell development at multiple levels, including reduced numbers of lymphoid progenitors generated in the BM, decreased clonal deletion during negative selection (which increases the risk of releasing autoreactive $\mathrm{T}$ cells in the periphery), altered thymic microenvironment, reduced output of new $\mathrm{T}$ cells $(6,10)$. As a result, it has been estimated that only $\sim 30-40 \%$ of elderly people are capable of mounting sufficient immune responses to the influenza vaccine (11). In addition, studies in pre-clinical models linked the skewed TCR repertoire occurring during aging to infection susceptibility (12). Although in healthy individuals thymic involution is not associated with any clinical consequences, the age-associated decline of thymic function significantly impairs the endogenous process of thymic repair following cytoreductive therapies further delaying the immune reconstitution in cancer patients (6).

Overall, reduction in thymic functionality and in the peripheral T-cell diversity are important contributors of the decline in immune surveillance observed in the elderly and this may eventually provide a supportive environment for infections and tumors to elude T-cell-mediated response. Even though there is a temporal correlation, the connection between decreased thymic function and increased incidence of cancers during age is still largely debated $(13,14)$.

\section{IMPACT OF THYMIC FUNCTION AND TCR DIVERSITY IN CLINICAL CONDITIONS}

In several clinical conditions, damage to thymic function and changes in TCR repertoire diversity correlate with patients' response to therapy and clinical outcome. In this section, we will provide a brief overview of how thymic functionality correlates with TCR diversity in human diseases and how TCR repertoire has been used to monitor and predict patient response to therapies.

Infections lead to severe thymic dysfunction, including reduced thymic output, altered thymic architecture and skewed TCR repertoire (15). Given that the degree of TCR diversity correlates with the chance of recognizing pathogenic antigens, the skewed TCR repertoire would probably represent a major factor in the reduced immune response to infections observed in HIV seropositive patients (16).

In patients affected by symptomatic SARS-CoV2 infection, lymphopenia, particularly in the CD8 + T cell compartment, has been shown to predict poor prognosis and can represent an early indicator for admission to the intensive care unit $(17,18)$. While there are not yet data on potential detrimental effects of SARSCov2 infection on thymic function, a recent study showed that Thymosin- $\alpha 1$ administration, which boosts immunity through thymic dependent and independent effects, increased survival of Covid-19 patients (19). Few studies are investigating the dynamic of TCR repertoire modification during infection demonstrating trends towards reduced TCR diversity in patients with pneumonia compared to those with mild disease (20). A clinical trial is ongoing to better characterize B- and Tcell repertoire and immune response in patients with acute and resolved Covid-19 infection (NCT04362865).

In patients receiving hematopoietic cell transplantation (HCT), impaired thymic function and suboptimal reconstitution of T-cell compartment have deleterious consequences. Thymic function is highly sensitive to conditioning regimens associated with the transplant procedure and delayed or defective recovery of its function has been linked to adverse clinical outcomes (21-24). Although mature $\mathrm{T}$ cells transferred with the graft or $\mathrm{T}$ cell clones resistant to conditioning procedure can expand and contribute to the recovery of the absolute lymphocyte counts early after HCT, the resulting T-cell immunity has a limited efficacy due to the skewed TCR repertoire. Low levels of tumor antigen-specific clonally expanded $\mathrm{T}$ cells are associated with higher risk of disease relapse (25). Indeed, higher TCR diversity has been correlated with lower relapse rates, presumably due to a greater probability of having $\mathrm{T}$ cell clones endowed with Graft-versus-Leukemia capacity (26). Similarly, delayed T-cell recovery and restricted TCR diversity post HCT are associated with increased risks of infection and leukemia relapse (27).

T-cell immunity is critical to control cancer occurrence and relapse; a more diverse TCR repertoire increases the likelihood of tumor-antigen recognition and mounting an effective immune response. For instance, reduced TCR diversity, when compared to healthy individuals, has been demonstrated in lung cancer patients (28). In addition, the TCR repertoire was particularly restricted in those patients carrying a more severe disease, which would indicate a defective antitumor immunity (28). In patients affected by cervical cancers, TCR repertoire diversity was lower than in patients with cervical intraepithelial neoplasia and healthy women, with a gradual decrease in TCR repertoire diversity during carcinogenesis and progression of the disease (29). Likewise, a recent study found that TCR repertoire diversity in renal cell carcinoma patients could predict better prognosis and the diversity was significantly higher in early disease stages. Interestingly, cytoreductive nephrectomy could restore TCR diversity, reduce $\mathrm{T}$-cell exhaustion and induce mobilization of naïve $\mathrm{T}$ cells (30).

\section{Checkpoint Blockade Immunotherapy}

Immunotherapy with monoclonal antibody-based immune checkpoint blockade (CBI) enhances the function of anti- 
tumor $\mathrm{T}$ lymphocytes in cancer patients, by targeting coinhibitory signaling pathways.

Cytotoxic T-Lymphocyte Antigen 4 (CTLA4) is an early negative regulator of $\mathrm{T}$-cell activation. It binds to CD80/CD86 (which provides co-stimulatory signal through CD28) and inhibits the acquisition of T-cell effector function. CTLA4 inhibits the priming of naive $\mathrm{CD} 4+\mathrm{T}$ cells and reduces the function of memory CD8+ T cells. CTLA4 is also expressed on $\mathrm{CD} 4+\mathrm{FOXP} 3+$ regulatory $\mathrm{T}$ cells (Tregs), contributing to their immunosuppressive property (31). Anti-CTLA4 monoclonal antibodies constrain Tregs immune suppression in the tumor microenvironment and enhance $\mathrm{CD} 4+$ and $\mathrm{CD} 8+\mathrm{T}$ cells primary and memory function (32). Anti-CTLA4 monoclonal antibodies are used in several clinical settings, including stage III/ IV melanoma, renal cell carcinoma, non-small-cell lung carcinoma (NSCLC) and prostate cancer (33).

Programmed death-ligand 1 (PD-L1) and 2 (PD-L2), expressed by tumor cells and tumor-associated APCs (in tumor inflammatory microenvironment), are Programmed Death 1 (PD1) ligands and represent important immune checkpoint molecules. The interaction between the ligand and its receptor inhibits T-cell effector activity (34), primary T-cell response (35) and inducible Tregs suppression function (36). Given the critical role of PD1 in mediating T-cell exhaustion, anti-PD1 blocking antibodies have been developed to restore effector function of anti-tumor T cells. Monoclonal anti-PD1 antibodies, either alone or in combination with other agents, are used to manage advanced cancer stages such as melanoma, advanced squamous-cell lung carcinoma, NSCLC, advanced renal cell carcinoma, recurrent squamous cell carcinoma of the head and neck, advanced hepatocellular carcinoma and Hodgkin Lymphoma. Monoclonal antibodies against PD-L1 are used in NSCLC, advanced urothelial carcinoma, metastatic Merkel cell carcinoma (31).

\section{TCR Repertoire Diversity and Patients' Response to $\mathrm{CBI}$}

The success of CBI depends on the presence of $\mathrm{T}$ cells able to recognize specific tumor antigens. The capacity of an individual to elicit an effective immune response is also directly correlated with tumor mutation load, which increases the likelihood of generating immunogenic neo-antigens and the chance to stimulate an anti-tumor immune response $(37,38)$. Thus, a broader TCR repertoire in patients receiving CBI would increase the chance of tumor antigen recognition and favorable long-term clinical outcome. Profiling TCR repertoire in patients before and after CBI has been used to assess dynamics of T-cell expansion and changes in T-cell clonotype diversity to predict and monitor patient response to therapy (39). Here we will highlight studies in which TCR diversity has been evaluated in the most commonly used CBI approaches: anti-CTLA4 e antiPD1/PD-L1.

Anti-CTLA4 therapy shapes T-cell pool involved in antitumor recognition by indiscriminately broadening blood TCR repertoire (which also increase treatment side effects) $(40,41)$ and by increasing the number of tumor reactive T-cell clones (42,
43). Indeed, it has been shown that anti-CTLA4 therapy drove polyclonal expansion of TCR clones in tumor microenvironment (44) even those not specific for tumor antigens $(45,46)$. Analysis of pre-treatment TCR clonality in metastatic melanoma patients suggested that T-cell clonality within the tumor did not predict response to CTLA4 blockade (47). On the other hand, melanoma patients receiving anti-PD1 therapy showed increased TCR clonality (which was ten times greater in responders than in non-responders) and reduction in TCR diversity of intratumoral infiltrating lymphocytes (47).

Studies have found that higher peripheral blood TCR diversity is associated with improved clinical outcome in melanoma patients receiving anti-CTLA4 $(48,49)$ or anti-PD1 therapy $(49)$. A similar study in melanoma patients observed that high pre-therapy clonality was associated with poor response to CTLA4, whereas it predicted good response to PD1 blockade (50). Higher baseline TCR diversity has been found to correlate with better disease control in patients with gastrointestinal cancers (51) and relapsed/refractory classical Hodgkin Lymphoma (52) receiving anti-PD1 therapy. Similarly, low T-cell clonality prior to anti-PD-L1 therapy and its increase in the periphery after immunotherapy has been associated with clinical benefits in patients with metastatic urothelial cancer (53). More recently, in a small group of patients affected by renal cell carcinoma receiving anti-PD1 therapy it was found which pretreatment TCR diversity could not predict patients' outcome and that restriction of TCR diversity early post-treatment (with following increase in TCR clonality) correlated with good response to therapy (54).

Thus, higher blood TCR diversity at baseline and increased TCR clonality following CBI have been associated with better clinical outcomes and increased survival in several studies, although not in all. Several factors can explain this discrepancy including the type of disease, the intra-tumoral mutation burden rate, patient previous therapies and method used to evaluate TCR diversity. In particular, the sample used to estimate TCR diversity could play a major role in the results. In addition to analysis in peripheral blood (which is representative of nontumor and tumor specific TCRs), specific blood T-cell subsets could better help to characterize the association between TCR diversity and response to CBI. For instance, peripheral PD1+ T cells, in the case of anti-PD1 blockade therapy, which should be representative of tumor-specific $\mathrm{T}$ cells $(46,55)$, may represent an ideal target to assess TCR diversity. Indeed, contrary to analysis performed on bulk CD8+ T cells, melanoma patients with higher pre-treatment TCR diversity and reduced diversity post anti-PD1 treatment in CD8+ PD1+ showed longer progression free survival (46). In addition, higher pretreatment TCR diversity on sorted PD1+ CD8+ T cells was also reported in those NSCLC patients with longer progressionfree survival and better overall survival before anti-PD1/PDL1 therapy (56).

Overall, a broader T-cell receptor before CBI immunotherapy has been largely associated with a better clinical outcome in cancer patients (Figure 1). This may suggest that approaches that improve TCR repertoire diversity could render more patients receptive to $\mathrm{CBI}$ treatment. 
As already discussed above, the decline of thymic function and the reduction of $\mathrm{T}$ cell repertoire diversity with age lead to holes in the repertoire that could compromise the efficacy of CBI. An increasing number of studies have been evaluating the possible association between age and response to CBI therapy in clinical studies, as well as in pre-clinical mouse models. In triple-negative breast cancer mouse model, one study demonstrated that young (8-12 weeks of age) and aged (>12 months of age) animals equally respond to anti-PD1. However, response to anti-CTLA4 therapy was significantly impaired in aged animals when tumor growth and survival were compared to young animals (57). Mechanistically, a lower number of infiltrating lymphocytes and a reduction in the expression of genes associated with antigen presentation and inflammation was observed in the tumor microenvironment of aged animals. Another study found that advanced age was associated with decreased overall survival in aged mice ( $>22$ months of age) treated with anti-PD1 (58). Interestingly, the same study also demonstrated that survival of glioblastoma patients were inversely correlated with CBI therapy as such that older patients have worse survival compared to younger patients.

However, a large amount of clinical evidence suggests that CBI therapy remains effective even in patients over the age of 75 and similar clinical response has been observed when patients are stratified by age $(59,60)$. For instance, response to CBI immunotherapy has been found to be independent of age in patients affected with IV stage melanoma and treated with antiCTLA4 (61). Surprisingly, other studies found that the response of melanoma patients to anti-PD1 was even better in older than in younger patients (62). A large meta-analysis of 19 CBI trials in advanced cancers found no significant association between age and response to therapy.

While multiple studies have found that age does not affect patients' response to CBI, this possibility is still under debate. In particular, as several of the reported studies are limited due to the retrospective nature of the analysis, prospective clinical studies that would include larger cohorts of elderly patients would be required to answer this question.

\section{MANIPULATING THYMIC FUNCTION TO ENHANCE EFFICACY OF CANCER IMMUNOTHERAPY}

Although the thymus is extremely sensitive to injury, it maintains a remarkable capacity for repair $(63,64)$. Therapies aimed to enhance the regeneration of thymic function are an attractive strategy to restore a diverse T-cell pool and long-term immunity (65). Several studies explored the use of regenerative factors to enhance and broaden immune responses in individuals with thymic insufficiency and immunodeficiency resulting from infections, cancer therapies and immunosenescence (Table 1 and Figure 1). Several therapies have been developed over time in preclinical models, some of which have been translated into clinical trials (5).

\section{IL-7}

One of the most widely studied molecules with immune regenerative capacity is the cytokine IL-7, a key lymphopoietic factor with the ability to enhance the proliferation of lymphocytes and lymphoid precursors (66). Several pre-clinical studies demonstrated that IL-7 cytokine controls the size of the peripheral T-cell pool and plays an important role in regulating overall T-cell homeostasis $(69,72)$. Moreover, in patients enrolled in a phase I dose-escalation trial, recombinant human IL-7 (rhIL-7) administration safely induced polyclonal T-cell expansion, resulting in increased T-cell counts. Specifically, 4 of the 6 enrolled subjects showed a statistically significant increase in TCR repertoire diversity 1 week after the end of rhIL-7 treatment compared to their baseline levels in $\mathrm{CD}^{+}$and $\mathrm{CD} 8{ }^{+}$ populations (73). RhIL-7 therapy also augmented immune responses to weak antigens and spare Tregs expansion (73). In a phase I clinical trial (NCT00684008) in which the immuneregenerative properties of rhIL-7 were assessed in patients receiving $\mathrm{T}$-cell-depleted allogeneic $\mathrm{HCT}$, the majority of participants displayed enhanced TCR repertoire diversity that persisted several weeks after the end of rhIL-7 therapy (70).

A recombinant form of the human interleukin-7 (NT-I7), in combination with PD-L1 inhibition, will be assessed in a Phase 2 study for the treatment of NSCLC patients.

\section{KGF}

Normal thymic T-cell development is strongly contingent on the regular maintenance of the stromal microenvironment. Thus, molecules that can promote recovery of stromal function, in particular of TECs, would support T-cell development and enhance $\mathrm{T}$-cell reconstitution after damage. Keratinocyte Growth Factor (KGF) is a potent growth factor expressed by thymic stroma that binds to its receptor on TECs and induces thymic epithelial cells (TEC) proliferation (115). Given its peculiarity to protect thymic stromal compartment from damage, KGF administration has been exploited in thymic regeneration therapies (116). The impact of exogenous administration of KGF on TEC function and thymic regrowth has been extensively assessed in several mouse studies. It has been found that KGF administration significantly increased thymic cellularity in mouse models of aging and following acute damage caused by radiation or chemotherapy $(88,117)$. Moreover, several studies in mice and non-human primates demonstrated the efficacy of KGF for improving thymicdependent T-cell recovery following HCT. In particular, KGFtreated animals showed increased numbers of $\mathrm{T}$-cell receptor excision circles (TRECs), which measure thymic function in peripheral blood, up to 3 months following treatment (118).

\section{RANKL}

The role of RANKL in the regeneration of the thymic microenvironment has been well characterized (82). Following thymic damage, RANKL induces up-regulation of lymphotoxin$\alpha$ (LT $\alpha)$ which can bind to LT $\beta$ receptor on thymic epithelial progenitor cells and TECs, and promote their regeneration (83). Exogenous administration of recombinant RANKL boosts 
TABLE 1 | Approaches, discussed in the review, to promote thymic function, their targets and their evaluation in clinical trials.

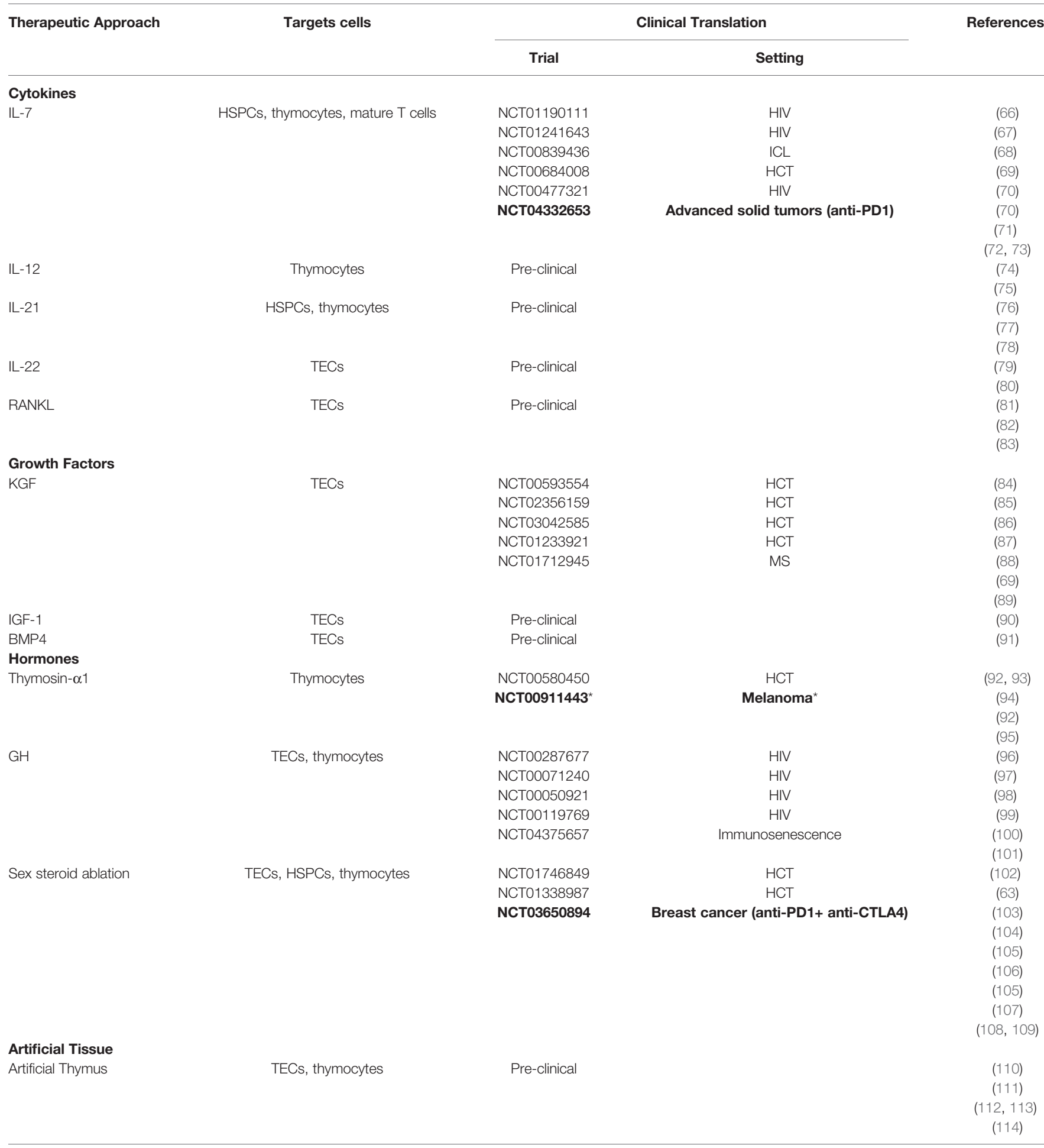

In bold, clinical studies on CBI in combination with immune boosting strategy. (GH, growth hormone; HSPCs, hematopoietic stem and progenitor cells; KGF, keratinocyte growth factor; IL, interleukin; RANKL, receptor activator of nuclear factor- $\mathrm{kB}$ ligand; TECs, thymic epithelial cells; IGF1, insuline-like growth factor 1; HCT, hematopoietic cell transplantation; MS, multiple sclerosis; ICL, Idiopathic CD4+ lymphocytopenia; HIV, Human Immunodeficiency Virus).

${ }^{*}$ Clinical trial on the efficacy of thymosin- $\alpha 1$ in combination with dacarbazine in melanoma patients. Patients were subsequently treated with anti-CTLA4 in a separate study. 
regeneration of TECs and improves T-cell progenitor homing and de novo thymopoiesis. Overall, these effects lead to enhanced T-cell development (81).

\section{Thymosin- $\alpha 1$}

Thymic stroma, particularly TECs, also produces Thymosin- $\alpha 1$ (T $\alpha 1)$ that is able to increase thymocytes differentiation, boost Tcell function and promote immune recovery following hematologic insults (119). Several evidence in pre-clinical models have highlighted the immunomodulatory properties of To1; thus, this therapy has been studied in the clinic for the treatment of patients experiencing viral infections, immunodeficiency and hematological malignancies (92, 94). Treatment with $\mathrm{T} \alpha 1$ resulted in earlier appearance of pathogen-specific $\mathrm{T}$-cell responses against pathogens such as cytomegalovirus and Aspergillus species after HCT (93). Interestingly, recent clinical studies also suggested that $\mathrm{T} \alpha 1$ may also have synergistic effects when used in combination with CBI. It has been shown that sequentially treatment with T $\alpha 1$ and anti-CTLA4 significantly increased overall survival of melanoma patients (95).

\section{Growth Hormone and Insulin-Like Growth Factor-1}

Growth Hormone $(\mathrm{GH})$ is a small peptide hormone implicated in the regulation of hematopoietic function. It has been demonstrated that in vivo administration of a recombinant form of GH or insulin-like growth factor-1 (IGF1) (which represents one of the principal mediators of GH effects) can reverse thymic involution, increases TCR diversity and enhances recovery of hematopoietic compartments in patients with adult GH deficiency $(90,101,120)$. Moreover, the administration of human recombinant $\mathrm{GH}$ in $\mathrm{HIV}$-infected patients promoted thymic function and peripheral immune function $(96,99)$. A recent study also suggested that $\mathrm{GH}$ treatment can regenerate thymic tissue in healthy adults between 51 and 65 years of age (100). This treatment resulted in significant increase of both $\mathrm{CD}^{+}$and $\mathrm{CD}^{+}$naive $\mathrm{T}$ cells, and in decrease of $\mathrm{PD} 1^{+} \mathrm{CD} 8^{+} \mathrm{T}$ cells (100).

\section{Ablation of Sex Steroids}

Sexual dimorphism in the immune system is well recognized and it is broadly summarized with the concept that women tend to develop more autoimmune diseases than men, while men are more vulnerable to some infectious diseases. Sex hormones, and in particular androgens, heavily influence thymic function primarily through the regulation of TEC differentiation and function $(121,122)$. Studies in murine models demonstrated that age-related thymic dysfunction is faster in males than in females. Similarly, in humans, the rate of thymic involution is greater in males as demonstrated by evaluation of TRECs in patient peripheral blood $(123,124)$. As direct evidence of the close connection between sex hormones and thymic function, many pre-clinical studies have demonstrated that sex steroid ablation (SSA), by surgical or chemical approaches, transiently reverses thymic involution and promotes rejuvenation of lymphoid tissues. SSA induces thymic reconstitution and peripheral immune cells recovery after radiation, chemotherapy and HCT (63, 104-107). Recent studies have also shown that the effects of SSA are not restricted to the lymphoid lineage, as extensive regenerative signals are also directed towards the hematopoietic stem and progenitor cells and their niche $(103,108)$. While the underlying mechanisms are still not completely understood, experimental evidence demonstrated that some of the regenerative effects are mediated by the removal of the inhibitory effects of sex steroids, primarily of androgens, on endogenous $\mathrm{B}$ and $\mathrm{T}$ lymphopoiesis. The increase in androgens during life could also explain and contribute to the faster rate of thymic-involution observed after puberty. Most of our mechanistic understanding of the effects of hormones on thymic function is largely restricted to the effects of androgens in male subjects. However, recent studies have started characterizing genders differences in thymic function and in response to SSA $(122,125)$. It has been shown that, in female mice, age induces a higher degree of central tolerance imbalance characterized by the reduction of medullary TECs expressing the autoimmune regulator gene (AIRE), which could contribute to the increased risk of autoimmune disease observed in middleaged women (126). In addition, middle-aged females are less affected by the regenerative effects triggered by SSA therapy compared to males but are more responsive when thymic regeneration was evaluated in response to acute thymic damage (125).

Interestingly, when transferred into the clinic, SSA has been shown to enhance neutrophil and lymphocyte recovery, thymic function and T-cell repertoire regeneration in patients receiving autologous and allogeneic HCT, independently from gender (109). Thus, while the precise mechanisms of action of SSA on lymphoid regeneration is still not completely understood, this approach represents an appealing therapy to enhance immune recovery in patients. Importantly, a clinical trial has been recently opened to evaluate if the regeneration of thymus and peripheral T-cell pool induced by SSA can enhance response to dual ICB with anti-PD1 and anti-CTLA4 therapy in metastatic breast cancer patients (127).

There is an incredible effort in the field to identify novel pathways and targets that can enhance thymic and immune recovery as the currently identified approaches are limited. In addition to IL-7, KGF, RANKL, SSA, GH and Thymosin $\alpha 1$, studies have found that other cytokines and growth factors have the potential to restore thymic function following immune insults. Administration of IL-12 induces thymocyte proliferation through increased IL-7 and IL-2 signaling (74). IL-21 delivery can also imprint regenerative signals to the thymus after immunological injuries such as glucocorticoidinduced thymic atrophy, aging and allogeneic HCT (76-78). IL-22 cytokine can mediate thymic regeneration by promoting TECs survival and proliferation through activation of STAT3 and STAT5 and expression of the antiapoptotic molecule Mcl1 $(80,128)$. Furthermore, BMP4 produced by thymic endothelial cells can drive thymic regeneration by binding to its receptor expressed on TECs and stimulating the upregulation of FoxN1 and its target genes (91). Critically, in patients with extensive thymic aplasia due to repetitive cycles of chemo or radiotherapy 
and/or aging, the presence of residual thymic tissue that could receive the regenerative signals and start organ recovery can be insufficient. In those conditions, the implant of artificial thymic tissue could represent an attractive alternative to repopulate the naive T-cell pool (110-114).

While some of the above-mentioned strategies have made some steps into the clinic, at present, there is no standard of care approach to promote immune reconstitution. In addition, their beneficial use in elderly cancer patients, which would greatly benefit from immune rejuvenating approaches, still requires additional research. Recent work observed that the increased disorganization and fibrosis of lymph nodes with age can limit the efficacy of thymic rejuvenation strategies (129). Thus, further studies are needed to determine whether secondary lymphoid organs are also rejuvenated with immune regenerative treatments, or whether approaches that could target both the thymus and the lymph nodes would represent a more effective therapy for immune recovery.

\section{Breaking Central Tolerance to Enhance CBI Efficacy}

Central tolerance takes place in the thymus, where $\mathrm{T}$ cell clones that are reactive to self are deleted to protect against the development of autoimmunity. Although on the one hand, this process allows the elimination of $\mathrm{T}$ cells reactive against tissuespecific self-antigens (130), on the other hand, the majority of tumor cells, which express self-antigens, could be recognized by the same self-reactive $\mathrm{T}$ cells deleted by negative selection in the thymus (131). AIRE plays a crucial role in establishing central T cell tolerance controlling the expression of tissue-specific selfantigens in medullary TECs. AIRE deficiency leads to multiple autoimmune disorders in mice and patients. AIRE knock-out mice, which show expanded auto reactive $\mathrm{T}$ cell repertoire, have enhanced ability to mount anti-tumor response when challenged with syngeneic melanoma cells (132). Interestingly, a polymorphism in AIRE, which can decrease the stability of the mRNA, has been associated with protection from melanoma (133). Thus, while protecting against autoimmunity, AIRE also limits antitumor immunity. Thus, recent studies have been investigating alternative approaches to enhance $\mathrm{T}$ cell-mediated antitumor immunity and response to CBI, which are based on temporary disruption of central $\mathrm{T}$ cell tolerance through the inhibition of AIRE (131). Evidence of this approach has been provided in pre-clinical settings by the infusion of anti-RANKL antibody, which depleted AIRE-expressing TEC in the thymus and allowed self/melanoma-reactive $\mathrm{T}$ cells to escape negative selection and increase in the peripheral pool. Combination of anti-RANKL and anti-CTLA4 antibody therapy enhanced antitumor response and survival after melanoma challenge (134). Similarly, the use of anti-RANKL/PD-1 dual targeting antibody has been shown to promote anti-tumor response in pre-clinical tumor models (135).

While the depletion of AIRE+ TECs and the suppression of central tolerance after anti-RANKL therapy could play an important role in the enhanced anti-tumor activity when combined with CBI, further studies are needed to better characterize the contribution of RANKL antagonism on the tumor microenvironment.

\section{CONCLUSIONS}

T-cell immunity is critical to control cancer occurrence and relapse. A more diverse TCR repertoire increases the likelihood of tumor-antigen recognition and of mounting an effective immune response. As the thymus represents the primary site of T-cell development and its function directly shapes the peripheral TCR diversity, robust residual thymic function in adult life can be associated with greater chance of establishing effective tumor immunity. However, direct evidence of the connection between thymic function and cancer is still under investigation. While thymic boosting approaches can have an immediate impact to enhance immune reconstitution after cytoreductive therapies, which would significantly reduce morbidly and improve survival in HCT patients, their potential use to extend the benefit of CBI is just beginning to be investigated. Indeed, although CBI has tremendously improved the chances of survival of cancer patients, a large proportion of them do not respond. Would patients with greater residual thymic functionality have greater chance to respond to CBI? In addition, multiple studies have investigated the use of TCR-seq as a predictive and prognostic tool for patient's response to CBI. Broader TCR diversity has been linked to greater response to $\mathrm{CBI}$ in multiple studies. However, the methodology is associated with significant cost and methodological bias. Thus, can the assessment of thymic function, for example through the evaluation of TRECs or recent thymic emigrants, better and more precisely stratify patients that could benefit from CBI? Clinical trials in progress will be fundamental to answer to these questions and explore these intriguing possibilities.

\section{AUTHOR CONTRIBUTIONS}

$\mathrm{AC}$ and $\mathrm{CD}$ conducted the literature review, created the figures, and wrote the bulk of the manuscript. FL contributed to writing and editing. EV conceived the review and contributed to the planning, editing and writing. All authors contributed to the article and approved the submitted version.

\section{FUNDING}

EV was supported by grants from the Amy Strelzer Manasevit Research Program; the Italian Association for Cancer Research (AIRC); and the Italian Ministry of Health ("Ricerca Corrente"). FL was supported by grants from AIRC (Special Program Metastatic disease: the key unmet need in oncology 5 per mille 2018 Project Code 21147 and Accelerator Award 2017 INCAR); Ministero dell'Istruzione, dell'Università e della Ricerca, PRIN ID 2017 WC8499_004; Ministero della Salute, RF-20 16-02364388. 


\section{REFERENCES}

1. Nikolich-Zugich J, Slifka MK, Messaoudi I. The Many Important Facets of T-Cell Repertoire Diversity. Nat Rev Immunol (2004) 4(2):123-32. doi: $10.1038 /$ nri1292

2. Takahama Y. Journey Through the Thymus: Stromal Guides for T-Cell Development and Selection. Nat Rev Immunol (2006) 6(2):127-35. doi: $10.1038 /$ nri1781

3. Hou X, Lu C, Chen S, Xie Q, Cui G, Chen J, et al. High Throughput Sequencing of T Cell Antigen Receptors Reveals a Conserved TCR Repertoire. Med (Baltimore) (2016) 95(10):e2839. doi: 10.1097/ MD.0000000000002839

4. Takahama Y, Ohigashi I, Baik S, Anderson G. Generation of Diversity in Thymic Epithelial Cells. Nat Rev Immunol (2017) 17(5):295-305. doi: 10.1038/nri.2017.12

5. Velardi E, Tsai JJ, van den Brink MRM. T Cell Regeneration After Immunological Injury. Nat Rev Immunol (2021) 21(5):277-91. doi: 10.1038/s41577-020-00457-z

6. Lynch HE, Goldberg GL, Chidgey A, Van den Brink MR, Boyd R, Sempowski GD. Thymic Involution and Immune Reconstitution. Trends Immunol (2009) 30(7):366-73. doi: 10.1016/j.it.2009.04.003

7. Yoshida K, Nakashima E, Kubo Y, Yamaoka M, Kajimura J, Kyoizumi S, et al. Inverse Associations Between Obesity Indicators and Thymic T-Cell Production Levels in Aging Atomic-Bomb Survivors. PLoS One (2014) 9(3): e91985. doi: 10.1371/journal.pone.0091985

8. Mold JE, Réu P, Olin A, Bernard S, Michaëlsson J, Rane S, et al. Cell Generation Dynamics Underlying Naive T-Cell Homeostasis in Adult Humans. PLoS Biol (2019) 17(10):e3000383. doi: 10.1371/journal.pbio.3000383

9. Nikolich-Zugich J. The Twilight of Immunity: Emerging Concepts in Aging of the Immune System. Nat Immunol (2018) 19(1):10-9. doi: 10.1038/ s41590-017-0006-x

10. Coder BD, Wang H, Ruan L, Su DM. Thymic Involution Perturbs Negative Selection Leading to Autoreactive T Cells That Induce Chronic Inflammation. J Immunol (2015) 194(12):5825-37. doi: 10.4049/ jimmunol.1500082

11. Thompson WW, Shay DK, Weintraub E, Brammer L, Cox N, Anderson LJ, et al. Mortality Associated With Influenza and Respiratory Syncytial Virus in the United States. JAMA J Am Med Assoc (2003) 289(2):179-86. doi: 10.1001/jama.289.2.179

12. Cicin-Sain L, Smyk-Pearson S, Currier N, Byrd L, Koudelka C, Robinson T, et al. Loss of Naive T Cells and Repertoire Constriction Predict Poor Response to Vaccination in Old Primates. J Immunol (2010) 184 (12):6739-45. doi: 10.4049/jimmunol.0904193

13. Palmer S, Albergante L, Blackburn CC, Newman TJ. Thymic Involution and Rising Disease Incidence With Age. Proc Natl Acad Sci USA (2018) 115 (8):1883-8. doi: 10.1073/pnas.1714478115

14. Jimenez-Alonso JJ, Calderon-Montano JM, Lopez-Lazaro M. Are Most Cancer Cases a Consequence of an Immune Deficiency Caused by Thymic Involution? Proc Natl Acad Sci USA (2018) 115(19):E4314-5. doi: 10.1073/pnas.1803180115

15. Savino W. The Thymus Is a Common Target Organ in Infectious Diseases. PLoS Pathog (2006) 2(6):e62. doi: 10.1371/journal.ppat.0020062

16. Heather JM, Best K, Oakes T, Gray ER, Roe JK, Thomas N, et al. Dynamic Perturbations of the T-Cell Receptor Repertoire in Chronic HIV Infection and Following Antiretroviral Therapy. Front Immunol (2015) 6:644. doi: 10.3389/fimmu.2015.00644

17. Liu Z, Long W, Tu M, Chen S, Huang Y, Wang S, et al. Lymphocyte Subset $(\mathrm{CD} 4+, \mathrm{CD} 8+)$ Counts Reflect the Severity of Infection and Predict the Clinical Outcomes in Patients With COVID-19. J infection (2020) 81 (2):318-56. doi: 10.1016/j.jinf.2020.03.054

18. Urra JM, Cabrera CM, Porras L, Rodenas I. Selective CD8 Cell Reduction by SARS-CoV-2 Is Associated With a Worse Prognosis and Systemic Inflammation in COVID-19 Patients. Clin Immunol (2020) 217:108486. doi: $10.1016 /$ j.clim.2020.108486

19. Liu Y, Pang Y, Hu Z, Wu M, Wang C, Feng Z, et al. Thymosin Alpha 1 (Talpha1) Reduces the Mortality of Severe COVID-19 by Restoration of Lymphocytopenia and Reversion of Exhausted T Cells. Clin Infect Dis an Off Publ Infect Dis Soc Am (2020) 71(16):2150-7. doi: 10.1093/cid/ciaa630
20. Chang CM, Feng PH, Wu TH, Alachkar H, Lee KY, Chang WC. Profiling of T Cell Repertoire in SARS-CoV-2-Infected COVID-19 Patients Between Mild Disease and Pneumonia. J Clin Immunol (2021) 41:1131-45. doi: 10.1007/s10875-021-01045-z

21. Atkinson K. Reconstruction of the Haemopoietic and Immune Systems After Marrow Transplantation. Bone Marrow Transplant (1990) 5(4):209-26.

22. Storek J, Witherspoon RP, Storb R. T Cell Reconstitution After Bone Marrow Transplantation Into Adult Patients Does Not Resemble T Cell Development in Early Life. Bone Marrow Transplant (1995) 16(3):413-25.

23. Weinberg K, Annett G, Kashyap A, Lenarsky C, Forman SJ, Parkman R. The Effect of Thymic Function on Immunocompetence Following Bone Marrow Transplantation. Biol Blood Marrow Transplant (1995) 1(1):18-23.

24. Velardi E, Clave E, Arruda LCM, Benini F, Locatelli F, Toubert A. The Role of the Thymus in Allogeneic Bone Marrow Transplantation and the Recovery of the Peripheral T-Cell Compartment. Semin Immunopathol (2021) 43(1):101-17. doi: 10.1007/s00281-020-00828-7

25. Kapp M, Stevanovic S, Fick K, Tan SM, Loeffler J, Opitz A, et al. CD8+ T-Cell Responses to Tumor-Associated Antigens Correlate With Superior RelapseFree Survival After Allo-SCT. Bone Marrow Transplant (2009) 43(5):399410. doi: 10.1038/bmt.2008.426

26. Yew PY, Alachkar H, Yamaguchi R, Kiyotani K, Fang H, Yap KL, et al. Quantitative Characterization of T-Cell Repertoire in Allogeneic Hematopoietic Stem Cell Transplant Recipients. Bone Marrow Transplant (2015) 50(9):1227-34. doi: 10.1038/bmt.2015.133

27. Van Heijst JWJ, Ceberio I, Lipuma LB, Samilo DW, Wasilewski GD, Gonzales AMR, et al. Quantitative Assessment of T Cell Repertoire Recovery After Hematopoietic Stem Cell Transplantation. Nat Med (2013) 19(3):372-7. doi: 10.1038/nm.3100

28. Liu YY, Yang QF, Yang JS, Cao RB, Liang JY, Liu YT, et al. Characteristics and Prognostic Significance of Profiling the Peripheral Blood T-Cell Receptor Repertoire in Patients With Advanced Lung Cancer. Int $J$ Cancer (2019) 145(5):1423-31. doi: 10.1002/ijc.32145

29. Cui JH, Lin KR, Yuan SH, Jin YB, Chen XP, Su XK, et al. TCR Repertoire as a Novel Indicator for Immune Monitoring and Prognosis Assessment of Patients With Cervical Cancer. Front Immunol (2018) 9:2729. doi: $10.3389 /$ fimmu.2018.02729

30. Guo L, Bi X, Li Y, Wen L, Zhang W, Jiang W, et al. Characteristics, Dynamic Changes, and Prognostic Significance of TCR Repertoire Profiling in Patients With Renal Cell Carcinoma. J Pathol (2020) 251(1):26-37. doi: 10.1002/path.5396

31. Hargadon KM, Johnson CE, Williams CJ. Immune Checkpoint Blockade Therapy for Cancer: An Overview of FDA-Approved Immune Checkpoint Inhibitors. Int Immunopharmacol (2018) 62:29-39. doi: 10.1016/ j.intimp.2018.06.001

32. Wei SC, Levine JH, Cogdill AP, Zhao Y, Anang NAS, Andrews MC, et al. Distinct Cellular Mechanisms Underlie Anti-CTLA-4 and Anti-PD-1 Checkpoint Blockade. Cell (2017) 170(6):1120-33.e17. doi: 10.1016/ j.cell.2017.07.024

33. Topalian SL, Drake CG, Pardoll DM. Immune Checkpoint Blockade: A Common Denominator Approach to Cancer Therapy. Cancer Cell (2015) 27 (4):450-61. doi: 10.1016/j.ccell.2015.03.001

34. Gordon J, Freeman AJL, Iwai $Y$, Bourque $K$, Chernova T, Nishimura $H$, et al. Engagement of the PD-1 Immunoinhibitory Receptor by a Novel B7 Family Member. J Exp Med (2000) 192(7):1027-34. doi: 10.1084/ jem.192.7.1027

35. Goldberg MV, Maris CH, Hipkiss EL, Flies AS, Zhen L, Tuder RM, et al. Role of PD- 1 and Its Ligand, B7-H1, in Early Fate Decisions of CD8 T Cells. Blood (2007) 110(1):186-92. doi: 10.1182/blood-2006-12-062422

36. Francisco LM, Salinas VH, Brown KE, Vanguri VK, Freeman GJ, Kuchroo VK, et al. PD-L1 Regulates the Development, Maintenance, and Function of Induced Regulatory T Cells. J Exp Med (2009) 206(13):3015-29. doi: $10.1084 /$ jem.20090847

37. Schumacher TN, Kesmir C, van Buuren MM. Biomarkers in Cancer Immunotherapy. Cancer Cell (2015) 27(1):12-4. doi: 10.1016/j.ccell.2014.12.004

38. McGranahan N, Furness AJ, Rosenthal R, Ramskov S, Lyngaa R, Saini SK, et al. Clonal Neoantigens Elicit T Cell Immunoreactivity and Sensitivity to Immune Checkpoint Blockade. Science (2016) 351(6280):1463-9. doi: $10.1126 /$ science.aaf1490 
39. Kidman J, Principe N, Watson M, Lassmann T, Holt RA, Nowak AK, et al. Characteristics of TCR Repertoire Associated With Successful Immune Checkpoint Therapy Responses. Front Immunol (2020) 11:587014. doi: 10.3389/fimmu.2020.587014

40. Cha E, Klinger M, Hou Y, Cummings C, Ribas A, Faham M, et al. Improved Survival With T Cell Clonotype Stability After Anti-CTLA-4 Treatment in Cancer Patients. Sci Transl Med (2014) 6(238):238ra70. doi: 10.1126/ scitranslmed.3008211

41. Oh DY, Cham J, Zhang L, Fong G, Kwek SS, Klinger M, et al. Immune Toxicities Elicted by CTLA-4 Blockade in Cancer Patients Are Associated With Early Diversification of the T-Cell Repertoire. Cancer Res (2017) 77 (6):1322-30. doi: 10.1158/0008-5472.CAN-16-2324

42. Hopkins AC, Yarchoan M, Durham JN, Yusko EC, Rytlewski JA, Robins HS, et al. T Cell Receptor Repertoire Features Associated With Survival in Immunotherapy-Treated Pancreatic Ductal Adenocarcinoma. JCI Insight (2018) 3(13):e122092. doi: 10.1172/jci.insight.122092

43. Robert L, Tsoi J, Wang X, Emerson R, Homet B, Chodon T, et al. CTLA4 Blockade Broadens the Peripheral T-Cell Receptor Repertoire. Clin Cancer Res (2014) 20(9):2424-32. doi: 10.1158/1078-0432.CCR-13-2648

44. Page DB, Yuan J, Redmond D, Wen YH, Durack JC, Emerson R, et al. Deep Sequencing of T-Cell Receptor DNA as a Biomarker of Clonally Expanded TILs in Breast Cancer After Immunotherapy. Cancer Immunol Res (2016) 4 (10):835-44. doi: 10.1158/2326-6066.CIR-16-0013

45. Simoni Y, Becht E, Fehlings M, Loh CY, Koo SL, Teng KWW, et al. Bystander CD8(+) T Cells Are Abundant and Phenotypically Distinct in Human Tumour Infiltrates. Nature (2018) 557(7706):575-9. doi: 10.1038/ s41586-018-0130-2

46. Gros A, Parkhurst MR, Tran E, Pasetto A, Robbins PF, Ilyas S, et al. Prospective Identification of Neoantigen-Specific Lymphocytes in the Peripheral Blood of Melanoma Patients. Nat Med (2016) 22(4):433-8. doi: $10.1038 / \mathrm{nm} .4051$

47. Whijae Roh P-LC, Reuben A, Spencer CN, Prieto PA, Miller JP, Gopalakrishna V, et al. Integrated Molecular Analysis of Tumor Biopsies on Sequential CTLA-4 and PD-1 Blockade. Cancer (2017) 9(379):eaah3560. doi: 10.1126/scitranslmed.aah3560

48. Postow MA, Manuel M, Wong P, Yuan J, Dong Z, Liu C, et al. Peripheral T Cell Receptor Diversity Is Associated With Clinical Outcomes Following Ipilimumab Treatment in Metastatic Melanoma. J Immunother Cancer (2015) 3:23. doi: 10.1186/s40425-015-0070-4

49. Arakawa A, Vollmer S, Tietze J, Galinski A, Heppt MV, Burdek M, et al. Clonality of CD4(+) Blood T Cells Predicts Longer Survival With CTLA4 or PD-1 Checkpoint Inhibition in Advanced Melanoma. Front Immunol (2019) 10:1336. doi: 10.3389/fimmu.2019.01336

50. Hogan SA, Courtier A, Cheng PF, Jaberg-Bentele NF, Goldinger SM, Manuel M, et al. Peripheral Blood TCR Repertoire Profiling May Facilitate Patient Stratification for Immunotherapy Against Melanoma. Cancer Immunol Res (2019) 7(1):77-85. doi: 10.1158/2326-6066.CIR-18-0136

51. Ji S, Li J, Chang L, Zhao C, Jia R, Tan Z, et al. Peripheral Blood T-Cell Receptor Repertoire as a Predictor of Clinical Outcomes in Gastrointestinal Cancer Patients Treated With PD-1 Inhibitor. Clin Transl Oncol (2021) 23 (8):1646-56. doi: 10.1007/s12094-021-02562-4

52. Cader FZ, Hu X, Goh WL, Wienand K, Ouyang J, Mandato E, et al. A Peripheral Immune Signature of Responsiveness to PD-1 Blockade in Patients With Classical Hodgkin Lymphoma. Nat Med (2020) 26(9):146879. doi: 10.1038/s41591-020-1006-1

53. Snyder A, Nathanson T, Funt SA, Ahuja A, Buros Novik J, Hellmann MD, et al. Contribution of Systemic and Somatic Factors to Clinical Response and Resistance to PD-L1 Blockade in Urothelial Cancer: An Exploratory MultiOmic Analysis. PLoS Med (2017) 14(5):e1002309. doi: 10.1371/ journal.pmed.1002309

54. Kato T, Kiyotani K, Tomiyama E, Koh Y, Matsushita M, Hayashi Y, et al. Peripheral T Cell Receptor Repertoire Features Predict Durable Responses to Anti-PD-1 Inhibitor Monotherapy in Advanced Renal Cell Carcinoma. Oncoimmunology (2021) 10(1):1862948. doi: 10.1080/2162402X. 2020.1862948

55. Huang AC, Postow MA, Orlowski RJ, Mick R, Bengsch B, Manne S, et al. TCell Invigoration to Tumour Burden Ratio Associated With Anti-PD-1 Response. Nature (2017) 545(7652):60-5. doi: 10.1038/nature22079
56. Han J, Duan J, Bai H, Wang Y, Wan R, Wang X, et al. TCR Repertoire Diversity of Peripheral PD-1(+)CD8(+) T Cells Predicts Clinical Outcomes After Immunotherapy in Patients With Non-Small Cell Lung Cancer. Cancer Immunol Res (2020) 8(1):146-54. doi: 10.1158/2326-6066.CIR-19-0398

57. Sceneay J, Goreczny GJ, Wilson K, Morrow S, DeCristo MJ, Ubellacker JM, et al. Interferon Signaling Is Diminished With Age and Is Associated With Immune Checkpoint Blockade Efficacy in Triple-Negative Breast Cancer. Cancer Discov (2019) 9(9):1208-27. doi: 10.1158/2159-8290.CD-18-1454

58. Ladomersky E, Zhai L, Lauing KL, Bell A, Xu J, Kocherginsky M, et al. Advanced Age Increases Immunosuppression in the Brain and Decreases Immunotherapeutic Efficacy in Subjects With Glioblastoma. Clin Cancer Res (2020) 26(19):5232-45. doi: 10.1158/1078-0432.CCR-19-3874

59. Kaiser M, Semeraro MD, Herrmann M, Absenger G, Gerger A, Renner W. Immune Aging and Immunotherapy in Cancer. Int J Mol Sci (2021) 22 (13):7016. doi: 10.3390/ijms22137016

60. Pawelec G. Does Patient Age Influence Anti-Cancer Immunity? Semin Immunopathol (2019) 41(1):125-31. doi: 10.1007/s00281-018-0697-6

61. Hodi FS, O'Day SJ, McDermott DF, Weber RW, Sosman JA, Haanen JB, et al. Improved Survival With Ipilimumab in Patients With Metastatic Melanoma. N Engl J Med (2010) 363(8):711-23. doi: 10.1056/ NEJMoa1003466

62. Kugel CH3rd, Douglass SM, Webster MR, Kaur A, Liu Q, Yin X, et al. Age Correlates With Response to Anti-PD1, Reflecting Age-Related Differences in Intratumoral Effector and Regulatory T-Cell Populations. Clin Cancer Res (2018) 24(21):5347-56. doi: 10.1158/1078-0432.CCR-18-1116

63. Goldberg GL, Dudakov JA, Reiseger JJ, Seach N, Ueno T, Vlahos K, et al. Sex Steroid Ablation Enhances Immune Reconstitution Following Cytotoxic Antineoplastic Therapy in Young Mice. J Immunol (2010) 184(11):6014-24. doi: 10.4049/jimmunol.0802445

64. van den Broek T, Delemarre EM, Janssen WJ, Nievelstein RA, Broen JC, Tesselaar K, et al. Neonatal Thymectomy Reveals Differentiation and Plasticity Within Human Naive T Cells. J Clin Invest (2016) 126(3):112636. doi: $10.1172 /$ JCI 84997

65. Roux E, Dumont-Girard F, Starobinski M, Siegrist CA, Helg C, Chapuis B, et al. Recovery of Immune Reactivity After T-Cell-Depleted Bone Marrow Transplantation Depends on Thymic Activity. Blood (2000) 96(6):2299-303. doi: 10.1182/blood.V96.6.2299

66. Chu YW, Memon SA, Sharrow SO, Hakim FT, Eckhaus M, Lucas PJ, et al. Exogenous IL-7 Increases Recent Thymic Emigrants in Peripheral Lymphoid Tissue Without Enhanced Thymic Function. Blood (2004) 104 (4):1110-9. doi: 10.1182/blood-2003-10-3635

67. Mackall CL, Fry TJ, Bare C, Morgan P, Galbraith A, Gress RE. IL-7 Increases Both Thymic-Dependent and Thymic-Independent T-Cell Regeneration After Bone Marrow Transplantation. Blood (2001) 97(5):1491-7. doi: 10.1182/blood.v97.5.1491

68. Fry TJ, Moniuszko M, Creekmore S, Donohue SJ, Douek DC, Giardina S, et al. IL-7 Therapy Dramatically Alters Peripheral T-Cell Homeostasis in Normal and SIV-Infected Nonhuman Primates. Blood (2003) 101(6):22949. doi: 10.1182/blood-2002-07-2297

69. Alpdogan O, Muriglan SJ, Eng JM, Willis LM, Greenberg AS, Kappel BJ, et al. IL-7 Enhances Peripheral T Cell Reconstitution After Allogeneic Hematopoietic Stem Cell Transplantation. J Clin Invest (2003) 112 (7):1095-107. doi: 10.1172/JCI17865

70. Perales MA, Goldberg JD, Yuan J, Koehne G, Lechner L, Papadopoulos EB, et al. Recombinant Human Interleukin-7 (CYT107) Promotes T-Cell Recovery After Allogeneic Stem Cell Transplantation. Blood (2012) 120 (24):4882-91. doi: 10.1182/blood-2012-06-437236

71. Sheikh V, Porter BO, DerSimonian R, Kovacs SB, Thompson WL, PerezDiez A, et al. Administration of Interleukin-7 Increases CD4 T Cells in Idiopathic CD4 Lymphocytopenia. Blood (2016) 127(8):977-88. doi: 10.1182/blood-2015-05-645077

72. Andrew D, Aspinall R. Il-7 and Not Stem Cell Factor Reverses Both the Increase in Apoptosis and the Decline in Thymopoiesis Seen in Aged Mice. J Immunol (2001) 166(3):1524-30. doi: 10.4049/jimmunol.166.3.1524

73. Sportes C, Hakim FT, Memon SA, Zhang H, Chua KS, Brown MR, et al. Administration of rhIL-7 in Humans Increases In Vivo TCR Repertoire Diversity by Preferential Expansion of Naive T Cell Subsets. J Exp Med (2008) 205(7):1701-14. doi: 10.1084/jem.20071681 
74. Li L, Hsu HC, Stockard CR, Yang P, Zhou J, Wu Q, et al. IL-12 Inhibits Thymic Involution by Enhancing IL-7- and IL-2-Induced Thymocyte Proliferation. J Immunol (2004) 172(5):2909-16. doi: 10.4049/ jimmunol.172.5.2909

75. Chen T, Burke KA, Zhan Y, Wang X, Shibata D, Zhao Y. IL-12 Facilitates Both the Recovery of Endogenous Hematopoiesis and the Engraftment of Stem Cells After Ionizing Radiation. Exp Hematol (2007) 35(2):203-13. doi: 10.1016/j.exphem.2006.10.002

76. Rafei M, Dumont-Lagace M, Rouette A, Perreault C. Interleukin-21 Accelerates Thymic Recovery From Glucocorticoid-Induced Atrophy. PLoS One (2013) 8(9):e72801. doi: 10.1371/journal.pone.0072801

77. Al-Chami E, Tormo A, Pasquin S, Kanjarawi R, Ziouani S, Rafei M. Interleukin-21 Administration to Aged Mice Rejuvenates Their Peripheral T-Cell Pool by Triggering De Novo Thymopoiesis. Aging Cell (2016) 15 (2):349-60. doi: 10.1111/acel.12440

78. Tormo A, Khodayarian F, Cui Y, Al-Chami E, Kanjarawi R, Noé B, et al. Interleukin-21 Promotes Thymopoiesis Recovery Following Hematopoietic Stem Cell Transplantation. J Hematol Oncol (2017) 10(1):120. doi: 10.1186/ s13045-017-0490-3

79. Dudakov JA, Mertelsmann AM, O'Connor MH, Jenq RR, Velardi E, Young LF, et al. Loss of Thymic Innate Lymphoid Cells Leads to Impaired Thymopoiesis in Experimental Graft-Versus-Host Disease. Blood (2017) 130(7):933-42. doi: 10.1182/blood-2017-01-762658

80. Pan B, Zhang F, Lu Z, Li L, Shang L, Xia F, et al. Donor T-Cell-Derived Interleukin-22 Promotes Thymus Regeneration and Alleviates Chronic Graft-Versus-Host Disease in Murine Allogeneic Hematopoietic Cell Transplant. Int Immunopharmacol (2019) 67:194-201. doi: 10.1016/ j.intimp.2018.12.023

81. Lopes N, Vachon H, Marie J, Irla M. Administration of RANKL Boosts Thymic Regeneration Upon Bone Marrow Transplantation. EMBO Mol Med (2017) 9(6):835-51. doi: 10.15252/emmm.201607176

82. Lee HW, Park HK, Na YJ, Kim CD, Lee JH, Kim BS, et al. RANKL Stimulates Proliferation, Adhesion and IL-7 Expression of Thymic Epithelial Cells. Exp Mol Med (2008) 40(1):59-70. doi: 10.3858/emm.2008.40.1.59

83. Borelli A, Irla M. Lymphotoxin: From the Physiology to the Regeneration of the Thymic Function. Cell Death Differ (2021) 28:2305-14. doi: 10.1038/ s41418-021-00834-8

84. Seggewiss R, Lore K, Guenaga FJ, Pittaluga S, Mattapallil J, Chow CK, et al. Keratinocyte Growth Factor Augments Immune Reconstitution After Autologous Hematopoietic Progenitor Cell Transplantation in Rhesus Macaques. Blood (2007) 110(1):441-9. doi: 10.1182/blood-2006-12-065623

85. Rizwan R, Levine JE, Defor T, Ferarra JL, Weisdorf DJ, Blazar BR, et al. Peritransplant Palifermin Use and Lymphocyte Recovery After T-Cell Replete, Matched Related Allogeneic Hematopoietic Cell Transplantation. Am J Hematol (2011) 86(10):879-82. doi: 10.1002/ajh.22136

86. Jacobson JM, Wang H, Bordi R, Zheng L, Gross BH, Landay AL, et al. A Randomized Controlled Trial of Palifermin (Recombinant Human Keratinocyte Growth Factor) for the Treatment of Inadequate CD4+ T Lymphocyte Recovery in Patients With HIV-1 Infection on Antiretroviral Therapy. J Acquir Immune Defic Syndr (2014) 66(4):399-406. doi: 10.1097/ QAI.0000000000000195

87. Coles AJ, Azzopardi L, Kousin-Ezewu O, Mullay HK, Thompson SA, Jarvis L, et al. Keratinocyte Growth Factor Impairs Human Thymic Recovery From Lymphopenia. JCI Insight (2019) 5. doi: 10.1172/jci.insight.125377

88. Rossi S, Blazar BR, Farrell CL, Danilenko DM, Lacey DL, Weinberg KI, et al. Keratinocyte Growth Factor Preserves Normal Thymopoiesis and Thymic Microenvironment During Experimental Graft-Versus-Host Disease. Blood (2002) 100(2):682-91. doi: 10.1182/blood.v100.2.682

89. Rossi SW, Jeker LT, Ueno T, Kuse S, Keller MP, Zuklys S, et al. Keratinocyte Growth Factor (KGF) Enhances Postnatal T-Cell Development via Enhancements in Proliferation and Function of Thymic Epithelial Cells. Blood (2007) 109(9):3803-11. doi: 10.1182/blood-2006-10-049767

90. Chu YW, Schmitz S, Choudhury B, Telford W, Kapoor V, Garfield S, et al. Exogenous Insulin-Like Growth Factor 1 Enhances Thymopoiesis Predominantly Through Thymic Epithelial Cell Expansion. Blood (2008) 112(7):2836-46. doi: 10.1182/blood-2008-04-149435

91. Wertheimer T, Velardi E, Tsai J, Cooper K, Xiao S, Kloss CC, et al. Production of BMP4 by Endothelial Cells Is Crucial for Endogenous
Thymic Regeneration. Sci Immunol (2018) 3(19):eaal2736. doi: 10.1126/ sciimmunol.aal2736

92. Ding J-H, Wang L-L, Chen Z, Wang J, Yu Z-P, Zhao G, et al. The Role of T $\alpha 1$ on the Infective Patients After Hematopoietic Stem Cell Transplantation. Int J Hematol (2013) 97(2):280-3. doi: 10.1007/s12185012-1208-5

93. Perruccio K, Bonifazi P, Topini F, Tosti A, Bozza S, Aloisi T, et al. Thymosin Alphal to Harness Immunity to Pathogens After Haploidentical Hematopoietic Transplantation. Ann NY Acad Sci (2010) 1194:153-61. doi: 10.1111/j.1749-6632.2010.05486.x

94. Wang F, Yu T, Zheng H, Lao X. Thymosin Alphal-Fc Modulates the Immune System and Down-Regulates the Progression of Melanoma and Breast Cancer With a Prolonged Half-Life. Sci Rep (2018) 8(1):12351. doi: 10.1038/s41598-018-30956-y

95. Danielli R, Cisternino F, Giannarelli D, Calabro L, Camerini R, Savelli V, et al. Long-Term Follow Up of Metastatic Melanoma Patients Treated With Thymosin Alpha-1: Investigating Immune Checkpoints Synergy. Expert Opin Biol Ther (2018) 18(sup1):77-83. doi: 10.1080/ 14712598.2018.1494717

96. Napolitano LA, Lo JC, Gotway MB, Mulligan K, Barbour JD, Schmidt D, et al. Increased Thymic Mass and Circulating Naive CD4 T Cells in HIV-1Infected Adults Treated With Growth Hormone. AIDS (2002) 16(8):110311. doi: 10.1097/00002030-200205240-00003

97. Chen BJ, Cui X, Sempowski GD, Chao NJ. Growth Hormone Accelerates Immune Recovery Following Allogeneic T-Cell-Depleted Bone Marrow Transplantation in Mice. Exp Hematol (2003) 31(10):953-8. doi: 10.1016/ s0301-472x(03)00196-6

98. Dixit VD, Yang H, Sun Y, Weeraratna AT, Youm YH, Smith RG, et al. Ghrelin Promotes Thymopoiesis During Aging. J Clin Invest (2007) 117 (10):2778-90. doi: 10.1172/JCI30248

99. Napolitano LA, Schmidt D, Gotway MB, Ameli N, Filbert EL, Ng MM, et al. Growth Hormone Enhances Thymic Function in HIV-1-Infected Adults. J Clin Invest (2008) 118(3):1085-98. doi: 10.1172/JCI32830

100. Fahy GM, Brooke RT, Watson JP, Good Z, Vasanawala SS, Maecker H, et al. Reversal of Epigenetic Aging and Immunosenescent Trends in Humans. Aging Cell (2019) 18(6):e13028. doi: 10.1111/acel.13028

101. Morrhaye G, Kermani H, Legros JJ, Baron F, Beguin Y, Moutschen M, et al. Impact of Growth Hormone (GH) Deficiency and GH Replacement Upon Thymus Function in Adult Patients. PLoS One (2009) 4(5):e5668. doi: 10.1371/journal.pone.0005668

102. Goldberg GL, King CG, Nejat RA, Suh DY, Smith OM, Bretz JC, et al. Luteinizing Hormone-Releasing Hormone Enhances T Cell Recovery Following Allogeneic Bone Marrow Transplantation. J Immunol (2009) 182(9):5846-54. doi: 10.4049/jimmunol.0801458

103. Velardi E, Tsai JJ, Radtke S, Cooper K, Argyropoulos KV, Jae-Hung S, et al. Suppression of Luteinizing Hormone Enhances HSC Recovery After Hematopoietic Injury. Nat Med (2018) 24(2):239. doi: 10.1038/nm.4470

104. Lai KP, Lai JJ, Chang P, Altuwaijri S, Hsu JW, Chuang KH, et al. Targeting Thymic Epithelia AR Enhances T-Cell Reconstitution and Bone Marrow Transplant Grafting Efficacy. Mol Endocrinol (2013) 27(1):25-37. doi: $10.1210 /$ me.2012-1244

105. Heng TS, Reiseger JJ, Fletcher AL, Leggatt GR, White OJ, Vlahos K, et al. Impact of Sex Steroid Ablation on Viral, Tumour and Vaccine Responses in Aged Mice. PLoS One (2012) 7(8):e42677. doi: 10.1371/journal.pone.0042677

106. Velardi E, Tsai JJ, Holland AM, Wertheimer T, Yu VWC, Zakrzewski JL, et al. Sex Steroid Blockade Enhances Thymopoiesis by Modulating Notch Signaling. J Exp Med (2014) 211(12):2341-9. doi: 10.1084/Jem.20131289

107. Dudakov JA, Goldberg GL, Reiseger JJ, Vlahos K, Chidgey AP, Boyd RL. Sex Steroid Ablation Enhances Hematopoietic Recovery Following Cytotoxic Antineoplastic Therapy in Aged Mice. J Immunol (2009) 183(11):7084-94. doi: 10.4049/jimmunol.0900196

108. Khong DM, Dudakov JA, Hammett MV, Jurblum MI, Khong SM, Goldberg GL, et al. Enhanced Hematopoietic Stem Cell Function Mediates Immune Regeneration Following Sex Steroid Blockade. Stem Cell Rep (2015) 4 (3):445-58. doi: 10.1016/j.stemcr.2015.01.018

109. Sutherland JS, Spyroglou L, Muirhead JL, Heng TS, Prieto-Hinojosa A, Prince HM, et al. Enhanced Immune System Regeneration in Humans Following Allogeneic or Autologous Hemopoietic Stem Cell 
Transplantation by Temporary Sex Steroid Blockade. Clin Cancer Res (2008) 14(4):1138-49. doi: 10.1158/1078-0432.CCR-07-1784

110. Fan Y, Tajima A, Goh SK, Geng X, Gualtierotti G, Grupillo M, et al. Bioengineering Thymus Organoids to Restore Thymic Function and Induce Donor-Specific Immune Tolerance to Allografts. Mol Ther J Am Soc Gene Ther (2015) 23(7):1262-77. doi: 10.1038/mt.2015.77

111. Shah NJ, Mao AS, Shih T-Y, Kerr MD, Sharda A, Raimondo TM, et al. An Injectable Bone Marrow-Like Scaffold Enhances T Cell Immunity After Hematopoietic Stem Cell Transplantation. Nat Biotechnol (2019) 37:293302. doi: 10.1038/s41587-019-0017-2

112. Otsuka R, Wada H, Tsuji H, Sasaki A, Murata T, Itoh M, et al. Efficient Generation of Thymic Epithelium From Induced Pluripotent Stem Cells That Prolongs Allograft Survival. Sci Rep (2020) 10(1):224. doi: 10.1038/ s41598-019-57088-1

113. Bredenkamp N, Ulyanchenko S, O'Neill KE, Manley NR, Vaidya HJ, Blackburn CC. An Organized and Functional Thymus Generated From FOXN1-Reprogrammed Fibroblasts. Nat Cell Biol (2014) 16(9):902-8. doi: $10.1038 /$ ncb3023

114. Bortolomai I, Sandri M, Draghici E, Fontana E, Campodoni E, Marcovecchio GE, et al. Gene Modification and Three-Dimensional Scaffolds as Novel Tools to Allow the Use of Postnatal Thymic Epithelial Cells for Thymus Regeneration Approaches. Stem Cells Transl Med (2019) 8(10):1107-22. doi: $10.1002 /$ sctm. $18-0218$

115. Finch PW, Rubin JS. Keratinocyte Growth Factor/Fibroblast Growth Factor 7, a Homeostatic Factor With Therapeutic Potential for Epithelial Protection and Repair. Adv Cancer Res (2004) 91:69-136. doi: 10.1016/S0065-230X(04) 91003-2

116. Alpdogan O, Hubbard VM, Smith OM, Patel N, Lu S, Goldberg GL, et al. Keratinocyte Growth Factor (KGF) Is Required for Postnatal Thymic Regeneration. Blood (2006) 107(6):2453-60. doi: 10.1182/blood-2005-072831

117. Min D, Panoskaltsis-Mortari A, Kuro OM, Hollander GA, Blazar BR, Weinberg KI. Sustained Thymopoiesis and Improvement in Functional Immunity Induced by Exogenous KGF Administration in Murine Models of Aging. Blood (2007) 109(6):2529-37. doi: 10.1182/blood-200608-043794

118. Wils EJ, Aerts-Kaya FS, Rombouts EJ, van Mourik I, Rijken-Schelen A, Visser TP, et al. Keratinocyte Growth Factor and Stem Cell Factor to Improve Thymopoiesis After Autologous CD34+ Cell Transplantation in Rhesus Macaques. Biol Blood Marrow Transplant (2012) 18(1):55-65. doi: 10.1016/j.bbmt.2011.09.010

119. Hirokawa K, McClure JE, Goldstein AL. Age-Related Changes in Localization of Thymosin in the Human Thymus. Thymus (1982) 4 (1):19-29.

120. Taub DD, Murphy WJ, Longo DL. Rejuvenation of the Aging Thymus: Growth Hormone-Mediated and Ghrelin-Mediated Signaling Pathways. Curr Opin Pharmacol (2010) 10(4):408-24. doi: 10.1016/j.coph.2010.04.015

121. Olsen NJ, Olson G, Viselli SM, Gu X, Kovacs WJ. Androgen Receptors in Thymic Epithelium Modulate Thymus Size and Thymocyte Development. Endocrinology (2001) 142(3):1278-83. doi: 10.1210/endo.142.3.8032

122. Wilhelmson AS, Lantero Rodriguez M, Johansson I, Svedlund Eriksson E, Stubelius A, Lindgren S, et al. Androgen Receptors in Epithelial Cells Regulate Thymopoiesis and Recent Thymic Emigrants in Male Mice. Front Immunol (2020) 11:1342. doi: 10.3389/fimmu.2020.01342

123. Just HL, Deleuran M, Vestergaard C, Deleuran B, Thestrup-Pedersen K. TCell Receptor Excision Circles (TREC) in CD4+ and CD8+ T-Cell Subpopulations in Atopic Dermatitis and Psoriasis Show Major Differences in the Emission of Recent Thymic Emigrants. Acta DermatoVenereologica (2008) 88(6):566-72. doi: 10.2340/00015555-0550
124. Pido-Lopez J, Imami N, Aspinall R. Both Age and Gender Affect Thymic Output: More Recent Thymic Migrants in Females Than Males as They Age. Clin Exp Immunol (2001) 125(3):409-13. doi: 10.1046/j.13652249.2001.01640.x

125. Hun ML, Wong K, Gunawan JR, Alsharif A, Quinn K, Chidgey AP. Gender Disparity Impacts on Thymus Aging and LHRH Receptor AntagonistInduced Thymic Reconstitution Following Chemotherapeutic Damage. Front Immunol (2020) 11:302. doi: 10.3389/fimmu.2020.00302

126. Fairweather D, Frisancho-Kiss S, Rose NR. Sex Differences in Autoimmune Disease From a Pathological Perspective. Am J Pathol (2008) 173(3):600-9. doi: 10.2353/ajpath.2008.071008

127. Page DB, Kim IK, Chun B, Redmond WL, Martel M, Mori M, et al. A Phase II Study of Dual Immune Checkpoint Blockade (ICB) Plus Androgen Receptor (AR) Blockade to Enhance Thymic T-Cell Production and Immunotherapy Response in Metastatic Breast Cancer (MBC). J Clin Oncol (2019) 37(15_suppl): TPS1106-TPS. doi: 10.1200/JCO.2019.37.15_suppl.TPS1106

128. Dudakov JA, Hanash AM, Jenq RR, Young LF, Ghosh A, Singer NV, et al. Interleukin-22 Drives Endogenous Thymic Regeneration in Mice. Science (2012) 336(6077):91-5. doi: 10.1126/science.1218004

129. Thompson HL, Smithey MJ, Uhrlaub JL, Jeftic I, Jergovic M, White SE, et al. Lymph Nodes as Barriers to T-Cell Rejuvenation in Aging Mice and Nonhuman Primates. Aging Cell (2019) 18(1):e12865. doi: 10.1111/acel.12865

130. Cheng M, Anderson MS. Thymic Tolerance as a Key Brake on Autoimmunity. Nat Immunol (2018) 19(7):659-64. doi: 10.1038/s41590018-0128-9

131. Wang W, Thomas R, Sizova O, Su DM. Thymic Function Associated With Cancer Development, Relapse, and Antitumor Immunity - A Mini-Review. Front Immunol (2020) 11:773. doi: 10.3389/fimmu.2020.00773

132. Trager U, Sierro S, Djordjevic G, Bouzo B, Khandwala S, Meloni A, et al. The Immune Response to Melanoma Is Limited by Thymic Selection of Self-Antigens. PLoS One (2012) 7(4):e35005. doi: 10.1371/journal. pone. 0035005

133. Conteduca G, Ferrera F, Pastorino L, Fenoglio D, Negrini S, Sormani MP, et al. The Role of AIRE Polymorphisms in Melanoma. Clin Immunol (2010) 136(1):96-104. doi: 10.1016/j.clim.2010.03.002

134. Bakhru P, Zhu ML, Wang HH, Hong LK, Khan I, Mouchess M, et al. Combination Central Tolerance and Peripheral Checkpoint Blockade Unleashes Antimelanoma Immunity. JCI Insight (2017) 2(18):e93265. doi: $10.1172 /$ jci.insight.93265

135. Dougall WC, Roman Aguilera A, Smyth MJ. Dual Targeting of RANKL and PD-1 With a Bispecific Antibody Improves Anti-Tumor Immunity. Clin Transl Immunol (2019) 8(10):e01081. doi: 10.1002/cti2.1081

Conflict of Interest: The authors declare that the research was conducted in the absence of any commercial or financial relationships that could be construed as a potential conflict of interest.

Publisher's Note: All claims expressed in this article are solely those of the authors and do not necessarily represent those of their affiliated organizations, or those of the publisher, the editors and the reviewers. Any product that may be evaluated in this article, or claim that may be made by its manufacturer, is not guaranteed or endorsed by the publisher.

Copyright $\odot 2021$ Cardinale, De Luca, Locatelli and Velardi. This is an open-access article distributed under the terms of the Creative Commons Attribution License (CC BY). The use, distribution or reproduction in other forums is permitted, provided the original author(s) and the copyright owner(s) are credited and that the original publication in this journal is cited, in accordance with accepted academic practice. No use, distribution or reproduction is permitted which does not comply with these terms. 